\title{
The incidence of pressure ulcers after the implementation of a prevention protocol ${ }^{1}$
}

\author{
Noemi Marisa Brunet Rogenski ${ }^{2}$ \\ Paulina Kurcgant ${ }^{3}$
}

\begin{abstract}
Even in the present, pressure ulcers still represent a severe health problem, particularly in Intensive Care Units (ICU). This study assesses the implementation of a protocol to prevent pressure ulcers in ICU inpatients. This prospective, descriptive and exploratory study verifies the incidence of pressure ulcers following the implementation of a prevention protocol. Data were collected from April $17^{\text {th }}$ to July $15^{\text {th }} 2009$. The incidence observed in this study $(23.1 \%)$ was below that reported in a similar study developed in the same institution $(41.02 \%)$ before the implementation of the protocols to assess risk and prevent pressure ulcers. The prevention protocols are essential tools that have an impact on controlling the incidence of pressure ulcers, when used consistently.

Descriptors: Pressure Ulcer; Incidence; Nursing.
\end{abstract}

\footnotetext{
1 Paper extracted from Doctoral Dissertation "Avaliação da implementação de um protocolo de prevenção de úlceras por pressão" presentd to Escola de Enfermagem, Universidade de São Paulo, Brazil.

${ }^{2}$ PhD, Divisão de Enfermagem Cirúrgica, Hospital Universitário, Universidade de São Paulo, Brazil.

${ }^{3} \mathrm{PhD}$, Full Professor, Escola de Enfermagem, Universidade de São Paulo, SP, Brazil.
}

Corresponding Author:

Noemi Marisa Brunet Rogenski

Universidade de São Paulo. Hospital Universitário

Av. Lineu Prestes, 2565

Bairro: Butantã

CEP: 05508-000, São Paulo, SP, Brasil

E-mail: noemi@hu.usp.br 


\section{Incidência de úlceras por pressão após a implementação de um protocolo de prevenção}

As úlceras por pressão, ainda hoje, representam sério problema de saúde, em particular nas unidades de terapia intensiva. O objetivo deste trabalho foi o de avaliar a implementação de um protocolo de prevenção de úlceras por pressão, em pacientes de Unidade de Terapia Intensiva. Como método, foi usado o estudo prospectivo, descritivo e exploratório em que se analisa a incidência de úlcera por pressão após a implementação de um protocolo de prevenção. Os dados foram coletados no período compreendido entre 17 de abril e 15 de julho de 2009. Vê-se, nos resultados, que a incidência encontrada nesse estudo $(23,1 \%)$ mostrou-se inferior àquela apontada em estudo similar, desenvolvido na mesma instituição $(41,02 \%)$, antes da implementação dos protocolos de avaliação de risco e prevenção de úlcera por pressão. Pode-se concluir que os protocolos de prevenção são ferramentas fundamentais e de impacto no controle da incidência de úlcera por pressão, quando utilizados sistematicamente.

Descritores: Úlcera por Pressão; Incidência; Enfermagem.

\section{Incidencia de las úlceras por presión tras la implementación de un protocolo de prevención}

Las úlceras por presión todavía representan un problema de salud grave, especialmente en unidades de cuidados intensivos. El objetivo de este estudio fue evaluar la aplicación de un protocolo para la prevención de úlceras por presión en pacientes de la Unidad de Cuidados Intensivos. Métodos: Estudio prospectivo, descriptivo y exploratorio, en los que la incidencia de úlceras por presión tras la aplicación de un protocolo de prevención. Los datos fueron recolectados durante el período comprendido entre el 17 abril a 15 julio 2009. Resultados: La incidencia encontrada en este estudio, el 23,1\%, fue inferior a la indicada en un estudio similar elaborado en la misma institución $(41,02 \%)$ antes de la aplicación de protocolos para la evaluación de riesgos y la prevención de úlceras por presión. Conclusiones: protocolos de prevención son herramientas fundamentales y el impacto en el control de la incidencia de úlceras por presión, cuando se usan de manera habitual.

Descriptores: Ulcera por Presión; Incidencia; Enfermería.

\section{Introduction}

Even though Pressure Ulcers (PU) have been much discussed and their causes, physiopathology and consequences are already known, they still represent a severe problem for institutionalized patients, as well as for the institution itself and the community.

It is currently clear that this phenomenon goes beyond nursing care because its etiology has a multifactor nature including factors intrinsic and extrinsic to the individual, such as age, comorbidities, mobility conditions, nutritional status, and level of awareness, among others. However, because the nursing staff provides direct care to patients and remains with them 24 hours a day, their role has been to implement preventive and systematized care measures through the adoption of protocols based on international guidelines to avoid such a threatening event.

Therefore, a study was conducted in the adult ICU of a university hospital in the city of São Paulo, SP, Brazil to verify the incidence of PUs since a high number of patients with PUs were identified in hospital facilities. A concern due to a lack of knowledge concerning the real scope of the problem, as well as a lack of protocols to guide the prevention and treatment of such lesions, led nurses to adopt the conduct they deemed most appropriate. 
After this study was conducted $^{(1)}$, an incidence of $41.02 \%$ was identified in the ICU and such a result prompted the Stomal Therapy Nursing Research Group at institution to develop a PU prevention protocol based on the guidelines of the National Pressure Ulcer Advisory Panel(2) as follows:

\section{PU prevention protocol}

Objective: to identify patients at risk of developing PUs and implement appropriate preventive interventions.

Proposal: to encourage prompt and effective care; standardize procedures; reduce costs; improve the patients' quality of life.

Definition: PUs refer to lesions located on the skin and/or tissue or subjacent structure, generally on a bone prominence, resulting from isolated pressure or pressure combined with friction and/or shear(3).

Nursing Interventions: Nurses should apply the Braden scale to all patients upon admission, at the time of the nursing assessment, and preventive measures should be applied whenever scores are equal to or below 16 .

Preventive interventions: Assess the patient's skin daily and change decubitus whenever in the presence of hyperemia; reassess after 30 minutes. If hyperemia does not disappear, confirm a stage I PU and implement the following measures:

- Change decubitus every two hours, or more frequently if necessary;

- Maintain a pneumatic mattress for patients at risk Braden score equal to or below 16;

- Avoid positioning the patient directly on trochanters. Keep the patient at a 30 degree angle (lateral position) with the aid of pillows and cushions;

- Change the patient's position carefully (i.e. to avoid attrition) to prevent lesions in fragile skin;

- Raise the bed head to the 30 degree position, at the most, if the patient's condition allows it and for the shortest period of time possible;

- Ask the nutritionist for nutritional support for patients identified as 'high risk' (Braden score equal to or below 11); - Protect bone prominences with pillows or cushions (i.e. knees and ankles);

- Maintain elevation of the heels with the aid of a proper cushion, preventing them from laying on the mattress;

- Minimize exposure of skin to moisture caused by incontinence, perspiration or drainage of fluids;

- Clean skin whenever needed and at regular intervals;

- Avoid using hot water and excessive friction during bathing;
- Use a gentle bath agent (glycerin soap) to minimize irritation and dryness;

- Use only gentle emollient immediately after bathing to protect and hydrate the skin (essential fatty acids) on elderly patients and those with dry skin;

- Avoid using tape on fragile skin;

- Use a skin protector (Cavilon ${ }^{\circledR}$ or extra thin hydrocolloid) before applying tape;

- Do not massage areas with hyperemia due to the risk of breaking vessels in the underlying tissues;

- Avoid massaging areas with bone prominences;

- Do not use donut ring pads, which may increase the area of ischemia;

- Reposition the patient every hour when seated;

- Protect the chair seat with a pressure reducing cushion;

- Observe and consider postural alignment, weight distribution, and stability when positioning the patient in a wheelchair;

- Instruct patients using wheelchairs to relieve pressure every 15 minutes;

- Instruct the patient and family members concerning preventive care measures;

The protocol was implemented in July 2005 after acquiring the required equipment and training the entire nursing staff. Thereafter, the facility started to consider the incidence of PUs as a quality indicator. However, no systematized studies were conducted after the protocol's implementation to verify the incidence of PUs or, consequently, the protocol's effectiveness. Hence, this study verifies the incidence of PUs in the adult ICU after the implementation of the PU prevention protocol and identifies the risk factors that most contributed to the development of PUs.

\section{Method}

This prospective, exploratory and quantitative study was conducted in a university hospital in the city of São Paulo, SP, Brazil. It is a general hospital of average treatment-complexity with 247 beds distributed into four basic specialties: surgical, medical, obstetrical and pediatric. The hospital's adult ICU is composed of 12 intensive care beds and eight beds reserved for semiintensive care.

Data collection was initiated after the Ethics Research Committee at the institution approved the project (CEPHU-USP:881/09-SISNEP-CAAE:0002.0.198.196-09). Those consenting to participate in the study signed free and informed consent forms. The researcher and five collaborators, previously trained to classify PUs and evaluate risk using the Braden scale, collected data. 
An instrument composed of four parts was used to collect data. The first part addresses the patients' sociodemographic data (age, gender, ethnicity, origin); the second regards clinical data such as primary disease, associated diseases, time of hospitalization, regularly taken medications, and Body Mass Index (BMI); the third part evaluated the patients' risk through the Braden scale; the fourth part recorded the characteristics of ulcers, whenever present, concerning number, site, and stag.

The stage of a PU was based on the international classification proposed by the National Pressure Ulcer Advisory Panel and revised in $2007^{(3)}$, when another two stages were added to describe tissue damage:

- Stage I - intact skin with non-blanchable hyperemia;

- Stage II - partial thickness loss of dermis;

- Stage III - Full thickness tissue loss;

- Stage IV - Full tissue loss with exposed bone, tendon or muscle;

- Unstageable - Full thickness tissue loss in which the base of the ulcer is covered by slough and/or eschar in the wound bed;

- Suspected deep tissue lesion - purple or maroon localized area of intact skin or blood-filled blister due to damage of underlying soft tissue from pressure and/or shear.

The number of new cases of patients with PUs developed within a certain period of time in a risk population transformed into a percentage was used to calculate the incidence ${ }^{(4)}$. Data were collected over three consecutive months, plus another ten days to perform a final assessment of all the patients. The first assessment was performed during the first 48 hours after admission and only the patients who present no PU at the first assessment were monitored. The patients with no ulcers but who presented a Braden score equal or below 16 continued to be assessed every Monday, Wednesday, and Friday until hospital discharge, transfer to other units or death. Every patient admitted during the data collection period was submitted to the same procedures.

Data were submitted to statistical treatment and Chi-square test or Fischer's exact test was used for the qualitative variables when necessary. Significance level was fixed at $5 \%$.

\section{Results}

A total of 78 patients at risk of developing PUs, that is, they scored equal or below 16 on the Braden scale were accompanied over three consecutive months. Of these, 18 developed a total of 23 PUs, representing an incidence of $23.1 \%$.

The patients' socio-demographic profiles indicate the age of patients with PUs ranged from 24 to 92 years old, with an average of 55 ( $S D=22.41) ; 34.4 \%$ of them were older than 60 years old. The age ranged from 18 to 88 years old among patients without PUs, with an average age of $55.1 \%(S D=20.04 \%) ; 40.0 \%$ were older than 60 years old. A predominance of male patients (66.7\% with PUs and $63.3 \%$ without PUs) was observed in the two groups, Caucasians $(83.3 \%$ and $73.3 \%$, respectively), non-smokers $(66.7 \%$ and $68.3 \%$, respectively), with primary and associated diseases compromising the digestive system (44.4\% with PUs and $28.3 \%$ without PUs) and the cardiovascular and respiratory system ( $27.8 \%$ and $36.7 \%$, respectively).

In relation to time of hospitalization, the stay of patients with PUs ranged from two to 37 days with an average of 11.83 days $(S D=9.96)$; seven of them (38.9\%) were hospitalized for more than 10 days. In the group without PUs, stays ranged from two to 41 days, with an average of 9.7 days $(S D=10.07)$ and 29 $(48.3 \%)$ of them stayed hospitalized less than five days.

Patients in both groups were within the healthy BMI range, and in relation to the use of medication, a predominance of cardiotonic and steroidal and nonsteroidal analgesics/anti-inflammatory drugs was observed in patients with PUs, while the use of cardiotonic and neuroleptics drugs was more predominant in the group without PUs.

Most patients $(14 / 77.8 \%)$ presented a single lesion. Lesions were most frequently located in the calcaneus $(42.1 \%)$, followed by the sacral region $(36.8 \%)$, buttocks $(15.8 \%)$ and trochanter $(10.5 \%)$. Most PUs (68.4\%) were in stage II; stage III and IV PUs were not found.

In relation to total scores obtained on the Braden scale, patients with PU predominantly presented highrisk scores (17/94.4\%); only one patient (5.6\%) presented moderate risk. Among those without PUs, $24(40.0 \%)$ were high-risk patients, while $51.7 \%$ were at low risk and $7.4 \%$ presented moderate risk for the development of PUs. The influence of the scores obtained on the Braden Scale (low, moderate, and high risk) was verified through logistic regression analysis. Therefore, high-risk patients had a 25.5 times greater chance of developing PUs than those considered to be at a low or moderate risk (Table 1 ). 
Table 1 - Logistic Regression of the Braden scale for the development of PUs in patients in the adult ICU. São Paulo, Brazil, 2010

\begin{tabular}{|c|c|c|c|c|c|}
\hline Variable & Coefficient & Descriptive level ( $p$-value) & Odds ratio (Exp (coef)) & Lower limit & Upper limit \\
\hline Scale's total score (high risk) & 3.24 & 0.002 & 25.50 & 3.18 & 204.50 \\
\hline
\end{tabular}

The most important risk factors contributing to the development and worsening of PUs according to the Braden scale were moisture, sensorial perception and mobility.

\section{Discussion}

Even though the ICU is the most appropriate unit to care for critical patients, some authors also consider it to be one of the most aggressive, stressful and traumatizing hospital environments for patients. There are, in addition to the patients' critical conditions, other factors that harm their psychological structure such as a lack of sleep conducive conditions, frequent therapeutic interventions, isolation, fear the disease may worse and fear of death, all of which interfere in their overall condition(5-6). Hence, patients bedridden for prolonged periods on mechanical ventilation, with motor and sensory dysfunction, using vasoactive drugs, are more susceptible to the development of PUs ${ }^{(7-9)}$.

Various studies addressing the incidence of PUs among inpatients were conducted in the last decade in Brazil. The studies reported incidences from $10.6 \%$ to $55 \%$, which varied according to the studied population, the inclusion of PUs in stage 1, and the methodology used. In relation to the incidence of PUs in ICUs, Brazilian authors report indices ranging from $25.8 \%$ to $62.5 \%$, which is above that (23.1\%) observed in this study(10-11).

Because the patients composing this study's sample were at risk of developing PUs, they presented similar socio-demographic and clinical characteristics. A predominance of male patients was observed in both groups, with and without PUs, Caucasians with an average age of 60 years old, living in the Butantã neighborhood, with an average BMI, that is, within the healthy range (18.50 to 24.99), most non-smokers, with an average of hospitalization of 9.7 days for the group without PUs and 11.83 days for those with PUs; primary diseases included digestive, cardiovascular, respiratory and musculoskeletal diseases. A total of 23 PUs were identified mainly located in the calcaneus $(8 / 42.1 \%)$, sacrum $(7 / 36.8 \%)$ buttocks and trochanter $(2 / 10.5 \%)$, areas receiving the greatest pressure in patients when in the dorsal position. These findings corroborate those reported by other studies ${ }^{(12)}$, in which most of ulcers affected the lower half of body due to the presence of large bony prominences and the uneven distribution of body weight in these areas.

The predominance of stage II PUs (64\%) observed in this study coincides with another study conducted in American acute care hospitals in which $90 \%$ of ulcers were either in stage $\mathrm{I}$ or $\mathrm{II}^{(13)}$ and with Brazilian studies $^{(1,14)}$ conducted in university hospitals, also reporting a predominance of stage I and II PUs.

Similar to the reports by other authors ${ }^{(1)}$, this study did not identify PUs in stage III or IV. It is worth noting that PUs found in the patients (stages I and II) did not progress to more advanced stages, probably due to the nursing staff's efforts to adopt preventive measures established in the protocol guiding proper care.

The literature shows that elderly individuals comprise the group with the highest risk for developing $\mathrm{PUS}^{(15)}$. Because their skin suffers changes inherent to the physiological aging process, such as reduced elasticity, texture, reduced muscle mass, and frequency of cell replacement, it becomes more fragile. These changes can lead to lesions induced by external factors such as pressure, friction, shear, and moisture. In this study, however, the age of patients with PUs ranged from 24 to 92 years old, with an average age of 55 years old. Some studies report that age was statistically significant while it is not statistically significant in others, indicating that such a factor cannot be considered in isolation ${ }^{(1,14-16)}$.

Most patients with PUs in this study had an associated disease that compromised their cardiovascular or respiratory systems (61.1\%), endocrine system (38.9\%), used cardiotonic medication (55.6\%), and steroidal and non-steroidal analgesics/anti-inflammatory drugs $(33.3 \%)$. It is known that patients using medication are susceptible to low sensory perception and consequently may have impaired mobility, and become more prone to the development of PUs ${ }^{(17)}$. Therefore, we note the importance for the nursing staff to systematically and routinely apply prevention strategies such as changing decubitus, using pressure-relieving mattresses, as well as the remaining measures recommended in the already established protocols.

The data analysis revealed that $94.4 \%$ of the patients with PUs were at a high risk of developing 
PUs and, according to the interpretation of the logistic regression coefficients, patients classified at a high risk according to the total score obtained on the Braden scale presented a 25.5 times greater chance of developing PUs than those at a low risk, due to their co-morbidities and overall conditions. We observed that $40 \%$ of the PUs developed in the fourth day of hospitalization and $90.4 \%$ of the total PUs developed within the first 15 days of hospitalization, which is in agreement with the literature, which establishes that the first 15 days of hospitalization are determinant in the development of PUs(18-19). The most important risk factors were established according to the average scores obtained by ICU inpatients with PUs on the Braden scale and moisture, sensory perception, and mobility appear as the first, second and third most important risk factors, respectively. We stress that when moisture alters the skin's pH (slightly acidic 5.5) toward more basic, the skin becomes fragile and more vulnerable to friction and shear. Patients become even more prone to the development of PUs if, coupled with fragile skin, the patient has compromised sensory perception, which reduces one's sensation of pain or discomfort, thus having no stimulus to move to obtain relief. These results underlie the need to reinforce specific instructions related to the priority of care and optimization of resources.

The incidence identified in this study $(23.1 \%)$ is below that reported in a similar study developed in the same facility $(41.02 \%)$ before the protocols to evaluate the risk of PUs and prevent them were implemented ${ }^{(1)}$.

\section{Final considerations}

The results showed a marked decrease in the incidence of PUs in the facility after the protocols of risk evaluation and prevention were implemented, confirming these are essential tools that have an impact on the control of the incidence of PUs when used consistently.

Nevertheless, further studies are needed to better identify the most important risk factors determining the development of PUs in the different stages, to establish cut-off scores on the Braden scale for specific populations, units and services as well as to address prevention cost effectiveness versus PU treatment, still incipient in the nursing field, in order to deepen knowledge and most of all, to delineate nursing as science.

\section{References}

1. Rogenski NMB, Santos VLCG. Estudo sobre a incidência de úlceras por pressão em um hospital universitário. Rev. Latino-Am. Enfermagem. 2005;13(4):474-80.
2. Agency for Health Care Policy and Research. Pressure ulcer in adults: prediction and prevention. Rockville (MD): U.S. Department of Health and Human Services; 1992.

3. National Pressure Ulcer Advisory Panel (US). Conceito e classificação de úlceras por pressão: atualização do NPUAP. Estima. 2007;5(3):43-4.

4. Frantz RA. Measuring prevalence and incidence of pressure ulcers. Adv Wound Care. 1997;10(1):21-4.

5. Gomes AM. Enfermagem na unidade de terapia intensiva. 2a ed. São Paulo: EDU; 1988.

6. Fernandes NCS, Torres GV. Incidência e fatores de risco de úlceras por pressão em pacientes de unidade de terapia intensiva. Cienc Cuid Saúde. 2008;7(3):304-10. 7. Backes DS, Guedes SMB, Rodrigues ZC. Prevenção de úlceras de pressão: uma maneira barata e eficiente de cuidar. Nursing. 1999;2(9):22-7.

8. Silva CC, Araújo VA, Silva ATMC. Formação de Força de Trabalho em Saúde: contribuição para a prática educativa em enfermagem. Cogitare Enferm. jan/mar 2008;13(1):10-7.

9. Cardoso MCS, Caliri MHL, Hass VJ. Prevalência de úlceras por pressão em pacientes críticos internados em um hospital universitário. Rev Min Enferm. 2004;8(2):316-20.

10. Louro M, Ferreira M, Povoa P. Avaliação de protocolo de prevenção e tratamento de úlceras por pressão. Rev Bras Ter Intensiva. 2007;19(3): 337-41.

11. Fernandes NCS, Torres GV. Incidência e fatores de risco de úlceras por pressão em pacientes de unidade de terapia intensiva. Cienc Cuid Saúde. 2008;7(3):304-10. 12. Maklebust J, Siegreen M. Pressure ulcers: prevention and nursing management. Pennsylvania: Springhouse; 1996.

13. Whittington K, Patrick M, Roberts JL. A national study of pressure ulcer prevalence and incidence in acute care hospitals, J Wound Care Nurs. 2000;27(4):209-15.

14. Costa IG, Caliri MHL. Incidência de úlceras de pressão em centro de terapia intensiva de um hospital universitário e fatores de risco relacionados. Rev Paul Enferm. 2005;23(3/4):202-7.

15. Margolis DJ, Bilker W, Knauss J, Baungarten M, Strom $\mathrm{BL}$. The incidence and prevalence of pressure ulcers among elderly patients in general medical practice. Ann Epidemiol. 2002;12(5):321-25.

16. Lobo A. Factores de riesgo em el desarrollo de úlceras por presión y sus implicaciones em la calidad de vida. Rev Bras Geriatr Gerontol. 2008;11(3):405-18. 17. Smith DM. Pressure ulcers in the nursing home. Ann Intern Med. 1995;123(6):433-42. 
18. Esperón Guimil J, Fernandez Camiña MC, Freire Rodriguez M, Angueira Castelo C, Rodrigues Fernandez C. La iatrogenis como origem de las úlceras por presión em uma Unidade de Cuidados Críticos. Gerokomos. 2005;16(2):100-8.

19. O'Neil CK. Prevention and treatment of pressure ulcers. J Pharm Pract. 2004;17(2);137-48. 